\title{
Research on Space Form in the Field of Architecture History GUO xiaoning ${ }^{1, a}$ \\ ${ }^{1}$ Xi'an University of Technology, Xi'an 710048,China \\ aguoxiaoning2013@yeah.net
}

keywords: Space form, Architecture, Structure

\begin{abstract}
Study on architecture theory allows us to further deepen the understanding of building and that of theories of architecture which have been concluded by our foremen. In the meantime, for the part of ancient and modern architectural history of different countries as well as different architecture forms produced under different ideologies, this passage is to help shape a preliminary understanding. What's more, architecture theory increases our understanding of as well as interest in the art of architectures from side face.
\end{abstract}

\section{Introduction.}

Architecture, head of eight forms of art, owns its special art appreciation and aesthetic shape, bringing people a sense of beauty. This passage is to introduce architecture in terms of space form in the field of architecture.

\section{Beauty of Form.}

\section{1 Major-minor and Focus.}

In a whole body constituted by several elements, proportion and position of each and every element of it will definitely have profound influence on the unity of the entire body. Competition and prominence of each element as well as equal positions of all elements will all weaken the complete unity of the whole body. In nature, limbs and branches, flowers and leaves of plants as well as bodies, arms and legs of animals demonstrate differences between the major and the minor, which help plants and animals shape a united and coordinated organic whole. Titles and subtitles, leading characters and protagonists, keys and the common also expresses a kind of relationship of master and slave.

\section{2 Symmetry and Balance.}

Symmetry means that all parts of the whole body shape equal corresponding relationships in accord with a real or fictitious symmetrical wheel or point, which possesses a kind of stable and united beauty. Balance is a rule of pattern developed from the laws of movements. Two sides of the wheel lines and support points form stability with different shapes but with same gravity. Balance is in the possession of instable loveliness and the law of balance make the forms of art change in the stability, taking shape a vivid and cute image. All of what symmetry and balance has shown to us is a kind of beauty of balance which is emphasized by us. And the reason why we give priority to it is because we focus on sense of balance in vision and are in pursuit of a kind of stable and safe feeling in our mind.

\section{3 Comparison and Harmony.}

Comparison means highlighting some contrast elements and making them more prominent with some variation principles, letting different elements attract each other and support each other to produce a simulating beauty in people's minds. There are many comparison elements in forms of art, such as big and small, straight and curled, directions, black and white, dark and light, tones, dense and sparse, real and fictitious, open and close. All of them are able to compare with each other. Harmony means different elements coordinating with each other or common points of some comparison elements. Comparison and harmony are indispensible, which means that comparison disappears without harmony and that comparison and harmony exist in a peaceful contradiction 


\section{4 Ratio Scale.}

Any forms of art contain the elements of ratio and scale. In terms of the laws of ratio and scale, the currently worldwide recognized golden ratio 1: 1.618 invented by Greet people is a kind of standard beauty. Therefore, those ratio relationships like 2:3, 3:5 and 5:8 which are approximate to 1:1.618 are called "golden ratio" and are able to mentally produce sense of beauty. People's bodies also have this kind of beautiful relationships, such as the ratio between upper and lower bodies of Venus, a world-renowned statue and the ratio of Parthenon Temple, an ancient Greet architecture. Both of them are close to golden ratio. Da Vinci, famous master of art, has exactly said in his work of art "Painting by Vinnci" that sense of beauty is supposed to be completely based on the holy ratio relationships of all parts.

\section{5 Rhythm and Rhyme.}

Rhythm exists in a great many real things around us, such as people's breathing, heart's beating and alternation of four seasons as well as day and night. Rhythm originally indicates the continuous orderly alternation of time, such as music rhythm. In works of art, rhythm means orderly and regular appearance of some shape elements, making people feel the mobilized continuity in vision and attain sense of rhythm mentally.

Rhyme is one of rhythm variations. It becomes rhythmic equally spaced intervals for the change in geometric progression, given repeated syllables or graphics to strengthen fluctuations, the cadence of the law changes, resulting in a beautiful rhythm .

Rhythm and rhyme are often interdependent, which is generally considered that the rhythm has a certain degree of mechanical beauty and rhyme produces endless fun in the changing of tempo, such as opposite growing, turning growing and alternating growing of plant leaves, from thick to thin , from sparse to dense, not only reflecting the change of tempo, but also the development of rhyme relations in the ever-changing images.

\section{6 Alternation and Unity.}

Alternation and unity are one of the most commonly used basic laws of formal beauty and both our living world and the entire universe are a rich and ever-changing whole contained by this law. In works of art, comprehensive effects of various elements make images abundant of change. However, this kind of change must reach high unity and most importantly be part of a center or a main body. Only in this way can an organic body be shaped, which is able to change with comparison and unite with coordination.

Beauty is a harmonious and united result created by various ratio relationships and opposite elements, which is called "change in the whole body". The law of diversity and unity is a conclusion of symmetry, balance, order, ratio, comparison, tempo, reality and fiction, master and servant as well as alternations. Besides, it is a law of beauty of form which must be conform to by all schools of art and an advanced law of beauty of form.

Diversity and unity are performances presented by dialectics law of opposites in natural science and social science as well as a general principle in all fields of art.

As a matter of fact, all of the above features are vital and indispensible in space forms in the field of architecture.

\section{Space of building.}

Space of building is enclosed from natural space by people with some special materials. However, once this kind of space of building is enclosed, its original attribute is transformed, changing from natural space to manual space.

People enclose space with two major service purposes. Firstly, satisfying some special functional needs, which is the most fundamental. Secondly, satisfying aesthetic requirements to some degree. As for the former requirement, it must conform to the rules of functions. Concretely speaking, the space enclosed must be in the possession of specific amount( size, volume), shape and materials which are able to shelter from rain, beat heat and cold and absorb more sunshine). In terms of the latter requirement, this kind of enclosed space must comply with laws of beauty, possessing 
demonstrating capability of art with unity, harmony and change.

Enclosure space is the means to achieve the double purposes above. In order to cost-effectively achieve the purposes, people must also play the mechanical properties of the materials, cleverly putting together the materials to bring about reasonable load transmission ways, making all parts of a whole have a certain rigidity and meet static balanced conditions .

\section{Basic laws of beauty of form applied on the building space of Taj Mahai.}

Taj Mahai, known as one of the most famous ancient relics in India, is named " perfect architecture” in India.

Taj Mahai consists of palaces, clock buildings, steeples as well as ponds, which have been built with pure white marbles as well as glasses and agates set in it, shining with unparalleled beauty. In addition, Taj Mahai has highly artistic value and is the representative of all Islam buildings. On July $7^{\text {th }}, 2007$, Taj Mahai was recognized as one of the eight wonders of the world.

\section{1 Major-Minor and focus of Taj Mahai.}

The entire park of Taj Mahai is shaped as a rectangle with a length of 576 meters, a width of 293 meters and a acreage of 170 thousand square meters. The four sides of Taj Mahai are surrounded by walls with red sands. In the center of Taj Mahai is the imperial tomb. And in the west and east of the imperial tomb are Masjid and Debating Hall whose building styles are identical. Besides, these two buildings are symmetrical and balanced.

On four sides of the imperial tomb are steeples, which are 40 meters long. In the meantime 50 -story stairs are built in the steeples provided for Islamic Missionary to ascend a height.

The center of the main building is towered by the platform and Masjid and Debating Hall surround the imperial tomb. The tall steeples in four directions also center the platform, indicating the prior position of central imperial tomb. Masjid and Debating Hall in the west and east as well as the steeples in four directions play the roles of minor parts.

Combination and distinguishing of the major and the minor are not only identified through the functions as well as their locating relationships of the buildings, but also through the mass relationship of the buildings.

\section{2 Comparison and harmony of Taj Mahai.}

Four small domes are compared with the big ones. Firstly, comparison of volume and size, contrasting the majesty of big domes. Secondly, comparison of false and true, contrasting the solemnity of the big domes.

Those thin and tall towers are compared with the tombs, indicating the magnificence and majesty of the tombs. In the meantime, all the domes, towered by the steady platform, are united because all of them are identical and closely linked to each other when building. Besides, the relationship between the big domes and the small domes coordinate and unite them all. The building material mainly used are white marbles. The upper part of the resting palace is a full and towering dome, the lower part of it is a tome jade with eight angles, half of the Koran stuck with black marbles in the door frames. Although the comparison between the black and the white is quite intense, they are united with each other and dull appearance is completely avoided.

In addition, subtle comparison between circles and squares, caves and cubes, weird shapes and common rectangles also acquire perfect effects to enrich the whole space. Due to the differences between the building elements, comparison will be more obvious. In terms of the beauty of form, obvious comparison and subtle comparison both play significant roles. Obvious comparison are able to be completed in various ways and subtle comparison are able to be coordinated through the continuity between them.

The lack of comparison will definitely make the whole image dull, but excessive comparison will make the image lose continuity and plunge into disorder. Only with the clever combination of them can we reach the effects of alternation and harmony. Comparison in the building image is mainly indicated through different volumes, shapes, directions, colors and textiles. 


\section{3 Symmetry and balance of Taj Mahai.}

Symmetry itself is balanced, the gate of Taj Mahai and the imperial tomb are connected by a wide and straight path laid with red stones, symmetrical and orderly between the left and the right. Along the two sides of the path are two pedestrian roads in the center of which a fountain shaped like “十” is built there. In front of Taj Mahai is a clear water tunnel along which apple trees and cypresses are planted, symbolizing life and death.

The symmetrical and long paths create a relaxing building space, contrasting with the large buildings in the distant and reaching an effect of balance. Green trees, clear water and white walls are also attracted with each other and an atmosphere of seriousness is made. With no doubt, the way of symmetry can certainly reach the effects of completeness and unity.

\section{Conclusion.}

To draw a conclusion from the example of Taj Mahai, the basic laws of space form are regularly applied in a broad way and it plays a significant role in architecture design. As for the study of architecture, we will deeply get an understanding of its basic laws and principles in the near future as it is truly indispensible in daily life.

\section{References}

[1] Cheng Dajin, Form, Space and Order of Architecture, Tianjin University Publication, 2011(90)

[2] Zhang Hongyuan, Beauty of Space Form, Peking University, 2009(102)

[3] Peng Yigang, Study on the Combination of Space, China Industrial Publication of Architecture, Beijing, 1983.

[4] Li Xiaodong, Appropriating Vernacular Space, International Architectural Education Forum, Nanjing 122-130

[5] Peter Allison, DAVID ADJAYE MAKING PUBLIC BUILDINGS SPECIFICITY CUSTOMIZATION IMBRICATION[M], 2006.Italy, 145-158 